\title{
BMJ Open Psychological problems and the associated factors related to the COVID-19 pandemic lockdown among college students in Amhara Region, Ethiopia: a cross-sectional study
}

\author{
Abay Woday Tadesse (D) ,,2 Setegn Tarekegn Mihret, ${ }^{3}$ Gebeyaw Biset (D) , ${ }^{4}$ \\ Ayesheshim Muluneh Kassa (i) ${ }^{5}$
}

To cite: Woday Tadesse A, Mihret ST, Biset G, et al. Psychological problems and the associated factors related to the COVID-19 pandemic lockdown among college students in Amhara Region, Ethiopia: a cross-sectional study. BMJ Open 2021;11:e045623. doi:10.1136/ bmjopen-2020-045623

- Prepublication history for this paper is available online. To view these files, please visit the journal online (http://dx.doi. org/10.1136/bmjopen-2020045623).

Received 12 October 2020 Accepted 29 July 2021

\section{A) Check for updates}

(c) Author(s) (or their employer(s)) 2021. Re-use permitted under CC BY-NC. No commercial re-use. See rights and permissions. Published by BMJ.

${ }^{1}$ Public Health, Samara University, Semera, Ethiopia ${ }^{2}$ Malaria and NTDs, Armauer Hansen Research Institute, Addis Ababa, Ethiopia

${ }^{3}$ Department of Nursing, Wollo University, Dessie, Ethiopia

${ }^{4}$ Pediatrics, Wollo University, Dessie, Ethiopia

${ }^{5}$ Nursing, Dessie Health Science College, Dessie, Ethiopia

Correspondence to Dr Abay Woday Tadesse; abaywoday@yahoo.com

\section{ABSTRACT}

Objective The central aim of this study was to assess the level of psychological problems among college students during school closure due to the emerging COVID-19 pandemic.

Design Institution-based, cross-sectional study. Setting Colleges in the Amhara regional state of Ethiopia. Participants Participants were college students $(\mathrm{N}=422$, $>18$ years) who were actively enrolled in the selected colleges preceding the survey.

Methods Data entry was done using Epi Info V.7.02 and data analysis was done using SPSS V.24.0. Variables with a $p$ value less than 0.25 in the bivariate analysis were entered into the multivariable logistic regression model. Model fitness was checked using the Hosmer-Lemeshow model fitness test. Statistically significant level was declared at $p<0.05$.

Outcome Level of psychological problem.

Results This study involved 408 students, with a response rate of $96.6 \%$. In this study, $77.2 \%, 71.8 \%$ and $48.5 \%$ of students experienced depression, anxiety and stress-related psychological problems during the lockdown, respectively. The multivariable logistic regression model showed that being female (adjusted OR $(\mathrm{AOR})=1.68,95 \% \mathrm{Cl} 1.09$ to 2.91 ), inadequate practice of prevention measures (AOR=1.74, 95\% $\mathrm{Cl} 1.01$ to 3.02 ) and living in an urban residency $(\mathrm{AOR}=0.76,95 \% \mathrm{Cl} 0.48$ to 0.94 ) were independent predictors of psychological problems among students.

Conclusions The study revealed that the level of anxiety, stress and depression disorders is optimally high among college students. Therefore, local governments should develop effective psychological interventions for students. Moreover, it is important to consider the educational enrolment type and the academic year of students.

\section{INTRODUCTION}

Severe acute respiratory infection (SARS) is a group of respiratory tract infections caused by a beta coronavirus (SARS-CoV-2). ${ }^{1}{ }^{2}$ COVID-19 is a family of SARS caused by novel coronavirus first detected in December 2019
Strengths and limitations of this study

School closure and stay-at-home declarations by the federal and lower government administrative exposed students to psychological problems.

- We used an internationally accepted tool to assess psychological problems: Depression, Anxiety and Stress Scale 21.

In this study, $77.2 \%, 71.8 \%$ and $48.5 \%$ of college students experienced depression, anxiety and stress-related psychological problems, respectively.

- The study was limited to college students due to financial constraints and may thus not represent students from high schools and precollege schools.

in Wuhan, China. The WHO has declared this disease a global pandemic and by the end of June 2021 has caused an estimated 134 million cases and nearly 4 million deaths. ${ }^{34}$ According to the Ethiopian Public Health Institute report, there have been an estimated 265350 confirmed cases and more than 3900 deaths in Ethiopia by the end of June 2021.

Countries across the globe have taken different preventive measures, including movement restrictions, home confinement, social distancing, lockdown and closure of schools, which led to increased psychosocial stress among the community, especially students. ${ }^{5-9}$

A study conducted in China revealed that $53.8 \%$ of the respondents experienced moderate to severe psychological crises, in which students were found to contribute a greater number than the larger communities. ${ }^{10}$ Another study in China revealed that around $25 \%$ of college students experienced anxiety due to the pandemic. ${ }^{11}$ A study also conducted in China revealed that $14.5 \%$, 
$8.9 \%$ and $7.7 \%$ of the participants screened positive for anxiety, depression and stress, respectively. ${ }^{12}$ Pieces of evidence had suggested that the pandemic resulted in loneliness, anxiety, depression, insomnia, suicide, impact on economic well-being, societal rejection, discrimination and stigmatisation among people. ${ }^{913-15}$

Ethiopia has taken different prevention and control measures to halt the spread of COVID-19. These include school closures, stay-at-home orders, keeping social and physical distances, placing hand- ashing basins in places where people commonly gather (banks, churches/ mosques, markets), preparation of isolation centres, and establishment of state emergency at the national level. ${ }^{16-18}$ However, there remains no specific intervention to address the psychological problems associated with COVID-19 in the country. Moreover, studies conducted across the globe that have investigated the psychological problems associated with the COVID-19 pandemic predominantly focused on healthcare workers and patients. ${ }^{19-21}$ Therefore, this study aimed to generate evidence on the prevalence of psychological problems due to COVID-19 and its determinants among college students.

\section{Specific objectives}

- To determine the prevalence of psychological problems related to the COVID-19 pandemic lockdown (depression, anxiety and stress) among college students in Amhara Region, Dessie Town in July 2020.

- To identify the factors associated with psychological problems related to the COVID-19 pandemic lockdown.

\section{METHODS}

\section{Study setting and participants}

This community-based, cross-sectional study was conducted from 15 April to 15 May 2020 to assess the psychological problems related to the COVID-19 pandemic among college students studying at four randomly selected private and public colleges and universities, namely Dream Science and Technology College, Dandii Boru College, Unity University and Dessie Health Science College. These higher institutions are found in South Wollo Zone, Dessie City Administration. Dessie City Administration is located $401 \mathrm{~km}$ away from the capital city of Ethiopia, Addis Ababa. The city has eight private colleges, one private university and three public colleges, which accommodate 20907 students in different fields of study.

All active students, registered for a second-semester academic year, and those 16 years of age and above were included in this study. Students who were seriously ill during the data collection period were not included in this study.

Sample size was calculated for both determinants and prevalence of psychological problems due to COVID-19 and the maximum sample size was considered for this study. Thus, the final sample size was determined using a single population proportion formula with the following assumptions: $5 \%$ type I error, $95 \% \mathrm{CI}$ and $50 \%$ proportion since there is no study on this problem in Ethiopia. Finally, the researchers added $10 \%$ to compensate for non-response of participants, arriving at a final sample size of 422.

$$
n=\frac{(\mathrm{Za} / \mathrm{z})^{2}(\mathrm{P})(1-\mathrm{P})}{\mathrm{d}^{2}}
$$

where $n=$ required sample size, $Z \alpha / 2=$ critical value for normal distribution at $95 \%$ confidence level (1.96), $\mathrm{P}=$ proportion of psychological problems and $\mathrm{d}=0.05(5 \%$ margin of error).

From a total of 12 colleges and universities found in Dessie City Administration, 4 higher institutions (3 colleges and 1 university) were randomly selected. The calculated sample size was proportionally allocated in each college based on the second-semester academic student number reports. To calculate the required number of participants from each college, we multiplied the total number of students actively learning in each college by the sampling fraction $(\mathrm{n} / \mathrm{N})$. The sampling fraction is approximately equal to six for all colleges. Accordingly, every sixth participant was selected using a systematic random sampling technique from each college registrar's office logbook.

\section{Study variables}

The dependent variable was the psychological problem related to the COVID-19 pandemic (yes/no) among college students and was assessed using the Depression, Anxiety and Stress Scale (DASS-21).

The independent variables were sociodemographic characteristics (age, residence, sex, marital status, educational level, field of study, income, family size, religion), knowledge, attitude and practice towards the preventive measures of COVID-19.

\section{Data collection tools and procedures}

The questionnaire was adopted from studies conducted before this study ${ }^{1122-24}$ and modified into context. The questionnaire was developed in the English language and consisted of sociodemographic characteristics, 20 items for knowledge, 8 items for attitude and 12 items for practice of preventive measures against COVID-19. The psychological problem was assessed using DASS$21,{ }^{25-27}$ which contains seven items for each psychological problem component. The tool was translated to the local language (Amharic) and back to English to keep their consistency. The tool was pretested on 5\% (21 participants) of samples other than the selected colleges found in the town of Woldia and some amendments were made based on the pretest findings. Data were collected using both phone call and personal interviews. Phone call was used for students who are out of Dessie Town. Trained health professionals who were working out of the selected colleges approached the study participants. 


\section{Data management and analysis}

Data were cleaned, coded and entered into Epi Info V.7.0.2 software and exported to SPSS V.24.0 for analysis. Descriptive statistics were done and the results were presented using text, frequency tables, figures and median with IQR.

Bivariate logistic regression analysis was done to assess the association between the dependent variable and each independent variable. The sociodemographic factors, knowledge, attitude and practice of preventive measures against COVID-19 were the factors included in the bivariate logistic regression analysis. Thus, independent variables with a $\mathrm{p}$ value of less than 0.25 were considered in the final model. Correlation between independent variables was assessed but we did not find any correlation between them. The model fitness was also checked using the Hosmer-Lemeshow model fitness test. Finally, multivariable logistic regression analysis was done to control for potential confounders and to identify the factors associated with the psychological problem due to COVID-19 among students. Statistical significance level was declared at $\mathrm{p}<0.05$.

\section{Operational definitions}

Psychological problem was defined as students who have experienced all forms of psychological problems (ie, depression, anxiety and stress) related to the COVID-19 pandemic and was measured using DASS-21. ${ }^{25-27}$ Here, the scales were classified as normal, moderate and severe for each psychological problem (depression, anxiety and stress). However, we merged moderate and severe scales together in each psychological problem measurement since the values for the moderate scale were minimal.

Knowledge level was defined as students who correctly answered $70 \%$ or more of the knowledge questions and were thus considered as students with good knowledge level. Students who correctly answered below $70 \%$ of the knowledge questions were considered to have poor knowledge.

Attitude level was defined as students who correctly answered $70 \%$ or more of the attitude questions and were thus considered as students with positive attitude. Students who correctly answered below $70 \%$ of the attitude questions were considered to have negative attitude.

Practice level was defined as students who correctly answered $70 \%$ or more of the practice questions and were thus considered as students with good practice level. Students who correctly answered below $70 \%$ of the practice questions were considered to have poor practice.

\section{Patient and public involvement statement}

No patients were involved.

\section{RESULTS}

Sociodemographic characteristics of participants

In this study, 408 participants were involved, with a response rate of $96.6 \%$. The median age of the participants was 21 years (IQR 3). Of the total number of students, $155(38.0 \%)$ lived in rural residences, $194(47.5 \%)$ were female, $215(52.7 \%)$ were learning Technical and Vocational Education and Training (TVET) or diploma-level training, and $340(83.3 \%)$ were living with their families during the COVID-19 lockdown. In this study, the participants had a median total family size of 5 (IQR 3) (table 1).

\section{Prevalence of psychological problems related to COVID-19}

In this study, the overall prevalence of psychological problem among college students due to COVID-19 was $16.2 \%$ (95\% CI $12.7 \%$ to $19.9 \%$ ), which was measured using students' experience of all forms of psychological problems (anxiety, depression and stress disorders). Moreover, 315 (77.2\%) students reported that they experienced depression disorder. Similarly, $293(71.8 \%)$ and $198(48.5 \%)$ students experienced anxiety and stress disorders, respectively (figure 1 ).

\section{Determinants of psychological problems related to COVID-19 among students}

The selection of variables to be entered into a multivariable logistic regression model was based on clinical significance, predictor variables with $\mathrm{p}<0.25$ in the bivariable logistic regression and absence of multicollinearity between independent variables. In this study, the selected covariates included sex of participants, residence, field of study, living conditions, attitude level and practice of preventive measures against COVID-19 and were entered into the multivariable logistic regression analysis model. The multivariable logistic regression model was done with backward elimination methods.

In this study, the odds of psychological problems due to COVID-19 among female students were two times higher compared with male students (adjusted OR $(\mathrm{AOR})=1.68$, 95\% CI 1.09 to 2.91). Students with inadequate practice of prevention and control measures experienced two times greater odds of psychological problems due to COVID-19 compared with students with adequate practices (AOR $=1.74,95 \%$ CI 1.01 to 3.02). Moreover, students living in an urban residency were $24 \%$ less likely to experience psychological problems compared with students currently living in rural areas $(\mathrm{AOR}=0.76,95 \%$ CI 0.48 to 0.94 ). Field of study, living conditions and attitude towards COVID-19 were not significantly associated with the psychological problems associated with COVID-19 among students (table 2).

\section{DISCUSSION}

COVID-19 has affected global mental health, as evidenced by the accelerated increase in cases and deaths related to the pandemic worldwide. ${ }^{28}$ In this study, the overall psychological problems related to COVID-19 among college students were measured using the experience of all forms of psychological problems (ie, anxiety, depression and stress disorders). Although the figure seems small, it represents the conjoined occurrence of psychological 
Table 1 Sociodemographics, knowledge, attitude and practices of students towards COVID-19

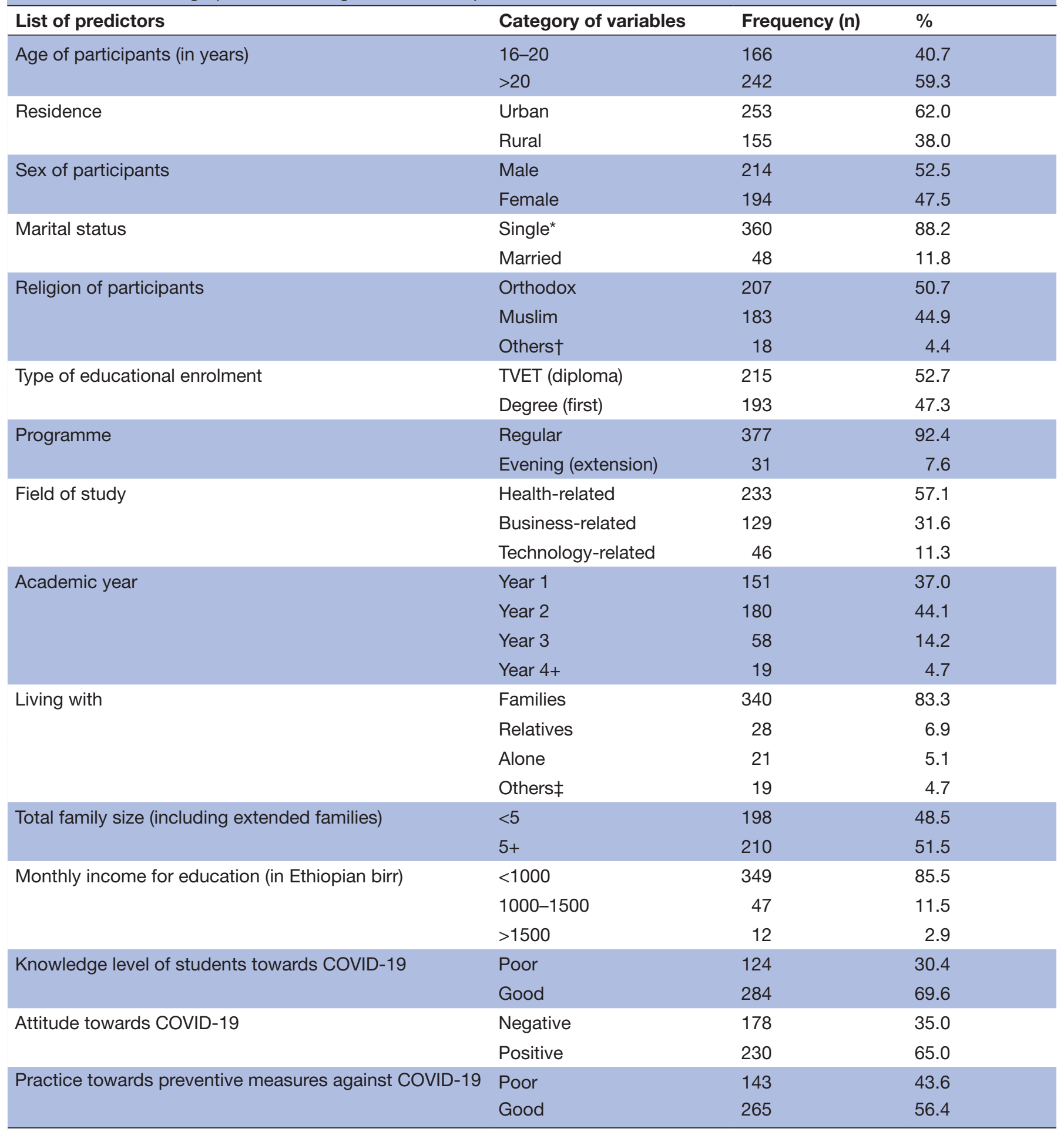

*Single: living together, divorced and widowed. †Others: Protestant and Catholic.

$\ddagger$ Others: friends, sisters-in-law/sons-in-law.

disorders reported by students. Thus, this prevalence is optimal compared with other similar studies conducted in developing countries which measured the situation of the problem using the existence of either of the three psychological problems. Furthermore, the multivariable logistic regression model showed that residence, poor practice and sex of participants were independent predictors of psychological problems related to COVID-19 among college students.

In this study, the overall psychological problem among college students due to COVID-19 was $16.2 \%$. This finding is lower than studies conducted in northern 
Type of psychological problems students experienced
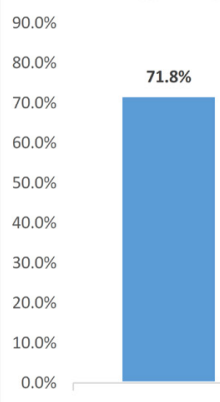

Anxiety
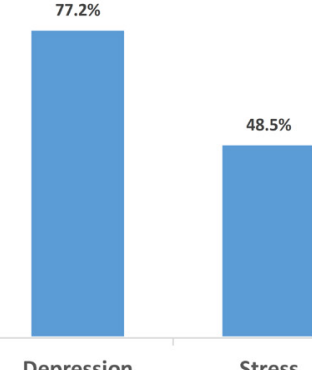

Stress

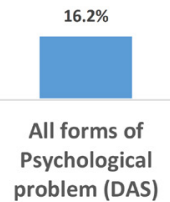

Figure 1 Types of psychological problems that students experienced during the COVID-19 lockdown. DAS, depression, anxiety and stress.

Ethiopia (85.3\%), ${ }^{20}$ University of Dhaka $(43.4 \%),{ }^{29}$ Jilin Province, China $(40.4 \%)^{30}$ and in 194 cities in China $(53.8 \%) .{ }^{31}$ The COVID-19 outbreak has caused psychological problems ${ }^{32}$ in the form of depression, anxiety and stress, which need provision of improved psychological interventions at the global, national, regional and district levels. The discrepancy might be due to differences in the measurement of the outcome variable (ie, psychological problem). In our study, psychological problem among students was measured using the coexistence of anxiety, stress and depression together, while in previous studies it was measured using either stress or anxiety or depression.

In our study, more than three-fourths $(77.2 \%)$ of the students reported to have had experienced depression disorder during the pandemic-related lockdown. This finding is higher than studies conducted in Hubei Province,
China $(37.1 \%),{ }^{33}$ in 194 cities in China $(16.5 \%)^{31}$ and in the findings of a systematic review $(14.6 \%-48.3 \%) \cdot{ }^{34}$ Similarly, our study showed that nearly three-fourths $(71.8 \%)$ of the students experienced anxiety disorders during the lockdown. This finding is higher than a study conducted in China which found only a quarter $(25 \%)$ of college students presented with anxiety disorder, ${ }^{11}$ a longitudinal study conducted in China (28.8\%). ${ }^{28}$ This finding is also higher than a study conducted in Hubei Province, China $(29 \%),{ }^{33}$ findings of a systematic review $(6.33 \%-50.9 \%)^{34}$ and a study in 194 cities in China (28.8\%). ${ }^{31}$ Moreover, in this study, nearly half $(48.5 \%)$ of the students experienced stress disorders during the lockdown. This finding is higher than a study conducted in Samara University, Northeast Ethiopia $(53.2 \%),{ }^{35}$ findings of a systematic review $(8.1 \%-81.9 \%)^{34}$ and a study in 194 cities in China $(8.1 \%) .{ }^{31}$ In Ethiopia, the widespread outbreak of COVID-19 is directly associated with these adverse psychological consequences among college students, who are out of school due to the national lockdown and school closure orders. Thus, students are more likely to suffer from the fear of the possibility that schools might not open again. On top of this, most of the college students were coming from the countryside to attend schools in towns and the national lockdown policy was declared before these students went back to their home villages. As a result, these students were likely to suffer from the fear of acquiring the newly emerged disease, COVID-19, compared with other community members.

In this study, the odds of psychological problems due to COVID-19 among female students were two times higher compared with male students. This finding is similar to a study conducted in Hubei Province, China, ${ }^{33}$ findings of a

Table 2 Factors associated with COVID-19-related psychological problems among college students in Ethiopia

\begin{tabular}{|c|c|c|c|c|c|}
\hline \multirow[b]{2}{*}{ List of variables } & \multirow[b]{2}{*}{ Category of variables } & \multicolumn{2}{|c|}{ Psychological problems } & \multirow[b]{2}{*}{ COR (95\% Cl) } & \multirow[b]{2}{*}{ AOR (95\% CI) } \\
\hline & & Yes (\%) & No (\%) & & \\
\hline \multirow[t]{2}{*}{ Residence } & Urban & 38 (57.6) & 215 (62.9) & 0.81 (0.47 to 1.37 ) & 0.76 (0.48 to 0.94$)^{x}$ \\
\hline & Rural & $28(42.4)$ & $127(37.1)$ & 1.00 & 1.00 \\
\hline \multirow[t]{2}{*}{ Sex of participants } & Female & $41(62.1)$ & $173(50.6)$ & 1.61 (0.93 to 2.75$)$ & $1.68(1.09 \text { to } 2.91)^{x}$ \\
\hline & Male & $25(37.9)$ & $169(49.4)$ & 1.00 & 1.00 \\
\hline \multirow[t]{3}{*}{ Field of study } & Health-related & $35(53.0)$ & $198(57.9)$ & 1.00 & 1.00 \\
\hline & Business-related & $23(34.8)$ & $106(31.0)$ & 1.23 (0.69 to 2.18 ) & 1.38 (0.74 to 2.57$)$ \\
\hline & Technology-related & $8(12.1)$ & 38 (11.1) & 1.19 (0.51 to 2.76$)$ & 1.54 (0.63 to 3.77 ) \\
\hline \multirow[t]{2}{*}{ Living with } & Family & $61(92.4)$ & $279(81.6)$ & 1.00 & 1.00 \\
\hline & Others $†$ & $5(7.6)$ & $63(18.4)$ & 0.36 (0.14 to 0.94$)$ & 0.94 (0.25 to 3.48$)$ \\
\hline \multirow{2}{*}{$\begin{array}{l}\text { Attitude towards } \\
\text { COVID-19 }\end{array}$} & Negative & $32(48.5)$ & $146(42.7)$ & 1.26 (0.76 to 2.14$)$ & 1.42 (0.81 to 2.51$)$ \\
\hline & Positive & $34(51.5)$ & $196(57.3)$ & 1.00 & 1.00 \\
\hline \multirow{2}{*}{$\begin{array}{l}\text { Practice towards } \\
\text { COVID-19 }\end{array}$} & Inadequate & $31(47.0)$ & $112(32.7)$ & 1.82 (1.07 to 3.10$)$ & 1.74 (1.01 to 3.02$)^{*}$ \\
\hline & Adequate & $35(53.0)$ & $230(67.3)$ & 1.00 & 1.00 \\
\hline
\end{tabular}

${ }^{*} \mathrm{P}<0.05$.

†Others: alone, relatives and friends.

AOR, adjusted OR; COR, crude OR. 
systematic review $^{34}$ and a study in Jilin Province, China. ${ }^{30}$ In Ethiopia, female students are prone to gender-based violence and poor social and economic support. ${ }^{35}$ Consequently, these conditions can easily lead them to lose their self-confidence and experience many stressors in life. Hence, they are more likely to suffer from psychological disorders (ie, depression, anxiety and stress) compared with their male counterparts.

This study revealed that students living in urban residences are $24 \%$ less likely to experience psychological problems compared with students currently living in rural areas. This finding is similar to a study conducted in China. ${ }^{11}$ Students in urban residences had more exposure to the media where they can get real information about safety measures and other preventive measures forwarded by the government and the international communities. Therefore, students living in urban residences were less likely to develop psychological problems compared with students in rural residences, where adequate information about the existing situation is not accessible.

In this study, students with poor preventive practice experienced two times greater odds of psychological problems due to COVID-19 compared with students with adequate practices. Previous studies revealed that students out of school and at the final stage of graduation are more prone to many psychological crises, ${ }^{830}$ which are due to poor adherence to the preventive measures against the COVID-19 pandemic.

\section{Limitations of the study}

This study mainly used self-reported questionnaires to measure psychiatric symptoms and did not make clinical diagnoses. This may overestimate the overall psychiatric symptoms, which in turn may increase the level of psychological problems among college students. Moreover, the study also shares the limitations of a cross-sectional study design.

\section{CONCLUSION}

In this study, the overall psychological problems among college students due to COVID-19 were comparable with other studies conducted across the developing world. Moreover, the level of anxiety, stress and depression disorders was optimally high among students. The multivariable logistic regression analysis showed residence, sex and level of preventive practice were independent predictors of psychological problems among students. Therefore, the Ministry of Science and Higher Education and local governments should develop effective strategies and interventions to address psychological problems among students. Moreover, it is important to consider the educational enrolment type and the academic year of students during the interventions.

Acknowledgements We would like to thank the Dream Science and Technology College for ethical approval. Furthermore, our deepest gratitude goes to the hospital staff, participants, data collectors and supervisors.
Contributors All authors conceived and designed the study. AWT and GB supervised the data collection. AWT, AMK and STM performed the data analysis, interpretation of data, drafted the manuscript and critically reviewed the manuscript. All authors read and approved the final manuscript.

Funding The authors have not declared a specific grant for this research from any funding agency in the public, commercial or not-for-profit sectors.

Competing interests None declared.

Patient and public involvement Patients and/or the public were not involved in the design, or conduct, or reporting, or dissemination plans of this research.

Patient consent for publication Not required.

Ethics approval Ethical approval was obtained from the Dream Science and Technology Institutional Health Research Ethics Review Committee with an approval letter (DSTC/DHS/031/2020). A permission letter was then written for selected colleges for cooperation and support. We had obtained verbal consent from individual study participants before starting the actual data collection. We avoided personal identifiers to ensure confidentiality and anonymity of study participants.

Provenance and peer review Not commissioned; externally peer reviewed.

Data availability statement Data are available upon reasonable request. All materials and data related to this article are included in the main document of the manuscript. However, if anyone has any interest to obtain raw data, he/she can contact the corresponding author.

Open access This is an open access article distributed in accordance with the Creative Commons Attribution Non Commercial (CC BY-NC 4.0) license, which permits others to distribute, remix, adapt, build upon this work non-commercially, and license their derivative works on different terms, provided the original work is properly cited, appropriate credit is given, any changes made indicated, and the use is non-commercial. See: http://creativecommons.org/licenses/by-nc/4.0/.

\section{ORCID iDs}

Abay Woday Tadesse http://orcid.org/0000-0003-0499-4690

Gebeyaw Biset http://orcid.org/0000-0002-8953-5022

Ayesheshim Muluneh Kassa http://orcid.org/0000-0003-4774-8107

\section{REFERENCES}

1 Wu D, Wu T, Liu Q, et al. The SARS-CoV-2 outbreak: what we know. Int $J$ Infect Dis 2020;94:44-8.

2 Zumla A, Hui DS, Perlman S. Middle East respiratory syndrome. Lancet 2015;386:995-1007.

3 WHO: coronavirus disease (COVID-19) situation report - 191, 2020. Available: https://www.who.int/emergencies/diseases/novelcoronavirus-2019/situation-reports-191

$4 \mathrm{Wu}$ Y, Ho W, Huang Y, et al. SARS-CoV-2 is an appropriate name for the new coronavirus. Lancet 2020;395:949-50.

5 Burke RM, Midgley CM, Dratch A, et al. Active Monitoring of Persons Exposed to Patients with Confirmed COVID-19 - United States, January-February 2020. MMWR Morb Mortal Wkly Rep 2020;69:245-6.

6 Zettler I, Schild C, Lilleholt L. Individual differences in accepting personal restrictions to fight the COVID-19 pandemic: results from a Danish adult sample, 2020.

7 Dong Y, Mo X, Hu Y, et al. Epidemiology of COVID-19 among children in China. Pediatrics 2020;145:e20200702.

8 Lee J. Mental health effects of school closures during COVID-19. Lancet Child Adolesc Health 2020;4:421.

9 Tran BX, Nguyen HT, Le HT, et al. Impact of COVID-19 on economic well-being and quality of life of the Vietnamese during the National social distancing. Front Psychol 2020;11:565153.

10 Wang C, Pan R, Wan X, et al. Immediate psychological responses and associated factors during the initial stage of the 2019 coronavirus disease (COVID-19) epidemic among the general population in China. Int J Environ Res Public Health 2020;17:1729.

11 Cao W, Fang Z, Hou G, et al. The psychological impact of the COVID-19 epidemic on college students in China. Psychiatry Res 2020;287:112934.

12 Liu N, Zhang F, Wei C, et al. Prevalence and predictors of PTSS during COVID-19 outbreak in China hardest-hit areas: gender differences matter. Psychiatry Res 2020;287:112921.

13 Xiang Y-T, Yang Y, Li W, et al. Timely mental health care for the 2019 novel coronavirus outbreak is urgently needed. Lancet Psychiatry 2020;7:228-9. 
14 Yao H, Chen J-H, Xu Y-F. Patients with mental health disorders in the COVID-19 epidemic. Lancet Psychiatry 2020;7:e21.

15 Le XTT, Dang AK, Toweh J, et al. Evaluating the psychological impacts related to COVID-19 of Vietnamese people under the first nationwide partial Lockdown in Vietnam. Front Psychiatry 2020;11:824.

16 Jemal B, Ferede ZA, Mola S. Knowledge, attitude and practice of healthcare workers towards COVID-19 and its prevention in Ethiopia: a multicenter study, 2020.

17 FMOH [Ethiopia]. COVID 19 Handbook for health professionals Federal Minstry of Health, Ethiopia, 2020. Available: https://www. FMOH.gov.et

$18 \mathrm{FMOH}$ [Ethiopia]. Infection prevention and control interim protocol for COVID-19 in health care settings in Ethiopia. Addis Ababa, Ethiopia: FMOH, 2020. https://www.FMOH.gov.et

19 McBride O, Murphy J, Shevlin M. Monitoring the psychological impact of the COVID-19 pandemic in the general population: an overview of the context, design and conduct of the COVID-19 Psychological Research Consortium (C19PRC) Study, 2020.

20 Tadesse DB, Gebrewahd GT, Demoz GT. Knowledge, attitude, practice and psychological response toward COVID-19 among nurses during the COVID-19 outbreak in northern Ethiopia. 2020, 2020.

21 Tan BYQ, Chew NWS, Lee GKH, et al. Psychological impact of the COVID-19 pandemic on health care workers in Singapore. Ann Intern Med 2020;173:317-20.

22 Joshi K, Jamadar D. Knowledge, attitude and practices regarding COVID-19 among medical students-A cross sectional study, 2020

23 Maheshwari S, Gupta PK, Sinha R. Attitude, and practice towards coronavirus disease 2019 (COVID-19) among medical students: a cross-sectional study. Journal of Acute Disease 2020:9:100.

24 Tee ML, Tee CA, Anlacan JP, et al. Psychological impact of COVID-19 pandemic in the Philippines. J Affect Disord 2020;277:379-91.
$25 \mathrm{Ng} \mathrm{F}$, Trauer T, Dodd S, et al. The validity of the 21-item version of the depression anxiety stress scales as a routine clinical outcome measure. Acta Neuropsychiatr 2007;19:304-10.

26 Wang C, Chudzicka-Czupała A, Grabowski D, et al. The association between physical and mental health and face mask use during the COVID-19 pandemic: a comparison of two countries with different views and practices. Front Psychiatry 2020;11:569981.

27 Le HT, Lai AJX, Sun J, et al. Corrigendum: anxiety and depression among people under the nationwide partial Lockdown in Vietnam. Front Public Health 2021;9:692085.

28 Wang C, Pan R, Wan X, et al. A longitudinal study on the mental health of general population during the COVID-19 epidemic in China. Brain Behav Immun 2020;87:40-8.

29 Imtiaz A, Hasan ME, Hossain MA. Attitudes toward COVID-19 among young adults: role of psychological distress, 2020

30 Liang L, Ren H, Cao R, et al. The effect of COVID-19 on youth mental health. Psychiatr Q 2020;91:841-52.

31 Qiu J, Shen B, Zhao M, et al. A nationwide survey of psychological distress among Chinese people in the COVID-19 epidemic: implications and policy recommendations. Gen Psychiatr 2020;33:e100213.

32 Duan L, Zhu G. Psychological interventions for people affected by the COVID-19 epidemic. Lancet Psychiatry 2020;7:300-2.

33 Ahmed MZ, Ahmed O, Aibao Z, et al. Epidemic of COVID-19 in China and associated psychological problems. Asian J Psychiatr 2020;51:102092.

34 Xiong J, Lipsitz O, Nasri F, et al. Impact of COVID-19 pandemic on mental health in the general population: a systematic review. J Affect Disord 2020;277:55-64.

35 Tesfaye Kelemu R, Bayray Kahsay A, Ahmed KY. Prevalence of mental distress and associated factors among Samara university students, northeast Ethiopia. Depress Res Treat 2020;2020:1-7. 